\title{
Bullet Richocheting and Riding the Easy Way - A Case Report
}

\author{
Authors \\ Dr Mohammad Mojahid Anwar', Dr Faiz Ahmad², Dr Mohammad Asrarul Haque ${ }^{3}$ \\ Dr Mohammad Adil ${ }^{4}$, Dr Munawwar Husain ${ }^{5}$, Dr Jawed Ahmad Usmani ${ }^{6}$ \\ Dr Baitullah ${ }^{7}$ \\ ${ }^{1}$ MBBS, D. Ophth, JR-III, Department of Forensic Medicine, \\ ${ }^{2}$ MBBS, JR-II, Department of Forensic Medicine \\ ${ }^{3}$ MBBS, MD, Senior Resident, Department of Forensic Medicine \\ ${ }^{4}$ MBBS, MD (Dermatology), Senior Resident, Department of Dermatology \\ ${ }^{5}$ MBBS, MD, DNB, MNAMS, Dip in Criminology \& Criminal Administration, Professor, \\ Department of Forensic Medicine \\ ${ }^{6}$ MBBS, MD (Path), MD (For Med), Dip in Criminology \& Criminal Administration \\ Professor \& Chairman Department of Forensic Medicine \\ J N Medical College, AMU, Aligarh 202002 \\ ${ }^{7}$ MBBS, MS, Professor, Department of Anatomy, Al Ameen Medical College, Bijapur, Karnataka \\ Corresponding author \\ Dr Faiz Ahmad \\ Email:faizahmad61@ gmail.com Mobile No. +91 7417593173
}

\begin{abstract}
A very visible and easily recognizable fire-arm entry wound was discernible on the right shoulder. No exit wound was found. It was assumed that the bullet may have struck a bone and would have rested at the site of impact. As is customarily and logically ordained in such matters an x'ray of right shoulder was advised. It was a shock at not finding the bullet at the end of track. The bullet was clearly found 6 inches below the wound on x'ray lying nose down and base up in perfectly perpendicular position. No fracture of bone was detected. This aspect and corresponding explanation forms the basis of this case report.

Keywords: bullet, richochet, pectoralis major, tumbling, wobbling, yaw
\end{abstract}

\section{Case Report}

A male victim of gunshot injury was brought to the Emergency Section of $\mathbf{J} \mathrm{N}$ Medical College Hospital, AMU, district Aligarh, in the first week of October 2015. He appeared to be 40 years old, robust in health. He was accompanied by his brother and other close relatives. $\mathrm{He}$ was conscious and did not appear to be frightened. The history about the incident was very brief and nonleading one. Allegedly he was shot after a brief altercation with the accused from a close range. He did not get the chance to dodge the bullet and took the fire standing upright facing the assailant. He saw that a revolver was used to fire upon him. 


\section{On Examination}

\section{General Examination}

His vitals were perfectly stable and within range. He appeared to be composed and gave the history himself without prompting by others. Occasionally he winced and told that he was having difficulty in inspiration. His chest circumference measured at the level of nipples by the flexible tape was:

Fully exhaled: $95.7 \mathrm{~cm}$

Fully inhaled: $97.4 \mathrm{~cm}$

\section{Local Examination}

A fire arm entry wound was present over the right shoulder 3 inches medial to the anterior axillary line and 7 inches below the acromion process.

\section{Description of the wound}

a) Central aperture $2.5 \mathrm{~cm}$, centrally placed, no beveling

b) Margins inverted

c) Bruising of margins present

d) No sign of singeing or soiling of wound

e) Tattooing was evident on the right hemisphere of central orifice

f) Contusion ring around the opening $(+)$

g) Marginal abrasion (+)

h) Active bleeding $(+)$

i) Collected blood was present around the wound as well as in the trickle downwards

j) A burnt hole on the right side of the shirt he was wearing at the time of assault was present corresponding to the site of fire arm wound.

There was no corresponding exit wound implying that the bullet must have been retained within the body itself. (Fig. 1)

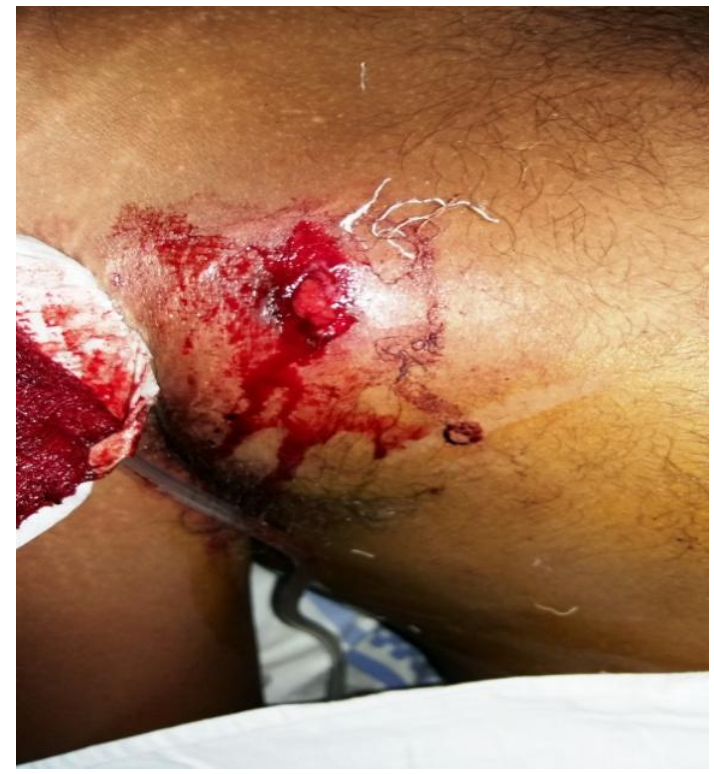

Fig.1

X'ray of chest - antero posterior view - showed the bullet held comfortably 10 inches below the actual wound. The .32 caliber bullet was lying at the level of $9^{\text {th }}$ and $10^{\text {th }}$ ribs on the right midclavicular line. The tip of the bullet was directed towards the lateral aspect of the chest and the base towards the lateral border of the sternum. It was held perfectly oblique in position with mathematical precision and showed absolutely no deviation towards the right or left plane. It appeared that the right convex dome of the diaphragm arrested its fall downwards. (Fig. 2)

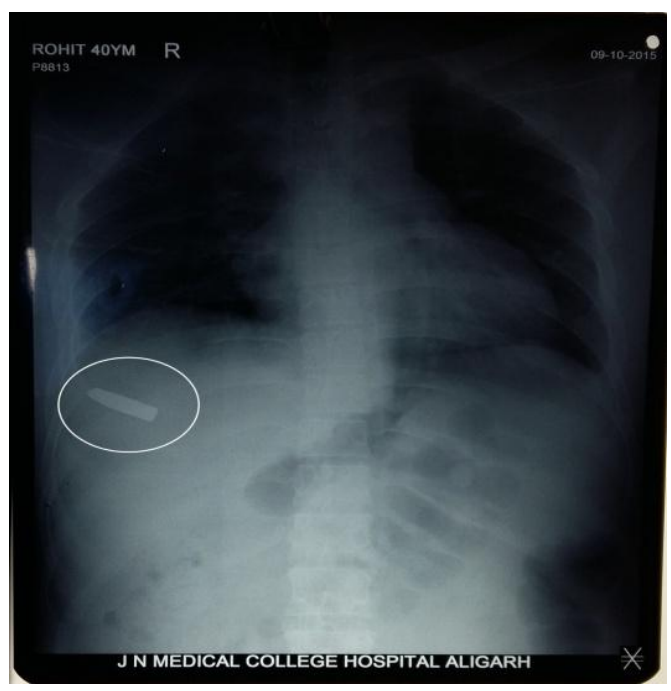

Fig. 2 


\section{Discussion}

This appears to be a remarkable case of richocheting of bullet. The sequence of events could be beaded together as follows:

The bullet may have been fired from an intermediate range. The kinetic energy of the bullet is high as it leaves the muzzle end of the fire arm. However, as it traverses the distance it is subjected to the gravitational pull, yaw, tumbling and wobbling phenomena ${ }^{1}$. The revolver is a low velocity fire-arm having a muzzle velocity of 600 $\mathrm{ft} / \mathrm{sec}$. Depending on the distance of the target the bullet may fiercely enter the body, or weakly pierce it or simply fall down after touching the body ${ }^{2}$. In this case it appears that the bullet may have been fired from an intermediate range $(\sim 2-3$ feet) ${ }^{3}$ and while striking the body at the pectoralis muscle it lost some of its momentum. It may have struck a stout rib, deviated and turned downwards. The force would be less so as not to fracture the rib. The 'function of pectoralis muscle is that it adducts, medially rotates and flexes arm. With arm fixed in abduction raises ribs (accessory muscle of inspiration), ${ }^{4}$ loosely covers the ribs to facilitate the breathing.

It could have happened that the man may have been in expiration phase allowing a brief relaxed interface between the ribs exactly at the moment he was fired upon. Consequentially the bullet trickled down and rested at the point of contact, i.e., resistance offered by the tough dome of diaphragm. (Fig. 2)

\section{Summary}

The experience of the authors and available literature it is beyond doubt that fire arm injury and missile may present in variable unpredictable pattern, some time far away from comprehension. This case represents one such behavior. However, if the events are pieced together sequentially than the final outcome could be reached fairly accurately.

\section{References}

1. Peitzman AB, Rhodes M, Schwab CW, Yealy DM, Fabian TC. The trauma manual. $2^{\text {nd }}$ ed. Publ. Lippincott Williams \& Wilkins, 2002; p10.

2. Franklin CA (ed): Modi's textbook of forensic medicine and toxicology. $21^{\text {st }}$ ed. Publ. N M Tripathi Pvt Ltd, 1988; p267.

3. Olshaker JS, Jackson MC, Smock WS. Forensic Emergency Medicine. $2^{\text {nd }}$ ed., Lippincott Williams \& Wilkins, p58.

4. Last RJ. Aids to anatomy. $21^{\text {st }}$ ed., Publ. bailliere, Tindall \& Cassell, 1962, p69. 